\title{
Automatic Plaster Machine
}

\author{
Keyur Sanjay Misar ${ }^{1}$ | P.M. Desai ${ }^{1}$ | Aishwarya Deepak Babar ${ }^{1}$ | Ankita Ramesh Ahire ${ }^{1}$ \\ ${ }^{1}$ Department of Electrical Engineering, Sandip Institute of Engineering and Management, Nashik, Maharashtra, India.
}

\section{To Cite this Article}

Keyur Sanjay Misar, P.M. Desai, Aishwarya Deepak Babar and Ankita Ramesh Ahire, "Automatic Plaster Machine", International Journal for Modern Trends in Science and Technology, Vol. 06, Issue 06, June 2020, pp.:182-185; https://doi.org/10.46501/IJMTST060633

\section{Article Info}

Received on 26-May-2020, Revised on 05-June-2020, Accepted on 13-June-2020, Published on 25-June-2020.

\section{ABSTRACT}

Presently, on the construction sites, because of the manual process of plastering the walls, there is large scale need of skilled labors and the higher labor costs are responsible for increasing the overall cost of construction of a building. The quality of plastering depends upon the skill of the labor in manual plastering method hence it contains irregular plastering surface which gives rise to risk and hazards to the infrastructure.

The solution of the above issues is just to introduce an automatic plastering machine which automates the process so as to save the time and money and achieve better quality of paltering. The finishing of the walls obtained from automatic plaster machine is very smooth and accurate as compared to manual process. Hence the machine is time saving, money saving hence the total cost of the project reduces which ultimately increases the progress rate of our nation

KEYWORDS: Labor cost, hopper, rope, motors, hazards, infrastructure, plastering, efficiency.

Copyright ( ) 2014-2020 International Journal for Modern Trends in Science and Technology

DOI: https://doi.org/10.46501/IJMTST060633

\section{INTRODUCTION}

Plaster is a material which is used in constructional sector for the protective or decorative coating of walls and ceilings. It can also be used to create architectural moldings. Plastering is a method which involves building of layers, the number of layers depends on the roughness of surface being plastered. The ones which are rough or bare walls require more coats of plaster while some might just require a finishing skin of 2 to $3 \mathrm{~mm}$.

Plastering is a labor-intensive process. Labors carry out the mixing and apply coating process, thus it becomes time consuming. As a result of human error, plastering done by labors has some drawbacks like dry lining, irregular plastering, loss of accuracy and precision in the thickness of the plastering, etc.
For the progress and economic growth of every country, construction sector is responsible, because evolution of the nation takes place when industrialization, civilization and transportation sectors increase their strength which initially comes from their building constriction.

Thus, the Automatic Plaster Machine replaces the labor and reduces the error caused. This machine is an innovative effort so as to improve the quality of the plastering, reduce overall cost of the project and reduce the time being taken for the construction.

\section{Problem Identification}

The process of wall plastering on construction sites is manual and hence there is large scale need of labors and the labors costs are too expensive hence this scenario is responsible for increasing the price 
of construction and project work. Also, the quality of the plastering work.

The quality of the plastering work depends upon the skills of the labor in manual process. The plastering achieved by labors contains irregulars of the surface of the plaster and usually is nonuniform. Thus, it affects the overall strength of the construction and threat is obtained.

Also, labors take more time to finish the work, they ask for breaks and holidays which enlarges the construction period. Skilled labors require more money and it increases the total cost of work which is very inefficient.

The building construction is time consuming sector since lot of work is labor based but, in every sector, plastering work is must so as to provide strength and protection to the infrastructure of the building.

Despite of significance to Indian Economy which is blessed with 26 million casual staff, there is no specific policy for ability building within the construction sector.

Following table shows the present pool of the development of manpower in republic of India contains principally unskilled workers.

\begin{tabular}{|l|lr|}
\hline CATEGORY & $\begin{array}{l}\% \\
\text { EMPLOYMENT }\end{array}$ & $\begin{array}{l}\text { TOTAL } \\
\text { EMPLOYMENT }\end{array}$ \\
\hline $\begin{array}{l}\text { Unskilled } \\
\text { labors }\end{array}$ & $83 \%$ & 25.6 million \\
\hline $\begin{array}{l}\text { Skilled } \\
\text { labors }\end{array}$ & $10 \%$ & 3.3 million \\
\hline Engineers & $3 \%$ & 0.8 million \\
\hline $\begin{array}{l}\text { Technicians } \\
\text { and foreman }\end{array}$ & $2 \%$ & 0.6 million \\
\hline Clerical & $2 \%$ & 0.7 million \\
\hline
\end{tabular}

In most of the countries, 10 to $20 \%$ of the GNP is for the construction industries which makes it largest economic employment sectors. Plastering is sensitive process if failed it can lead to excess shrinkage and cracking if precision is avoided which ultimately leads to dangerous hazards and risks the human life.

\section{OBJECTIVES}

Due to the manual process of wall plastering on construction site, there is a huge scale requirement of labor which in turn increases the costing of project work. The quality of work depends on the degree of skill the labors have in manual plastering process. This problem can be solved by just automating the process which is the main objective also include:

1. Saving of time period and cost.

2. Achieving good plaster finishing to the walls.

3. It will reduce human work.

4. It will be portable.

5. Machine cost will be less than the cost of existing methods.

6. Accuracy and precision in thickness of the plaster.

7. Saving raw material wastage.

8. Easy operation.

9. Machine control using remote controller.

\section{PRE-PLASTERING REQUIREMENTS}

The pre-plastering requirements include following aspects:

- The structure of the bricks should be in the proper manner i.e. it should form a flat surface all over its area i.e. with its height, length and breath.

- $3 \mathrm{~mm}$ deviation is allowable over the $1200 \mathrm{~mm}$ radius.

- The surface i.e. where the machine is going to be installed for plastering should be flat so that the base of the machine remains same during its operation.

The mixture of the plaster should be poured in the proportion of $4: 1$ i.e. cement and sand respectively.

\section{DESIGN OF THE MACHINE COMPONENTS}

i. Weight / Load On the Container:

Container Specifications $=12 * 12 * 6(1 * \mathrm{~b} * \mathrm{~h})$ Inches.

i.e. $30.48 \mathrm{~cm} * 30.48 \mathrm{~cm} * 15.24 \mathrm{~cm}$

Height of the poles for lifting up the container $=36$ Inches i.e. $91.44 \mathrm{~cm}$.

Plastering Width $=10$ inches $=25.4 \mathrm{~cm}$.

Plastering Height $=28$ inches $=71.12 \mathrm{~cm}$.

Plastering Thickness $=0.3937$ inches $=$ $1 \mathrm{~cm}$.

Mortar Mixing Proportions $=4: 1$ (cement: sand) universal.

Let us consider $2 \mathrm{~kg}$ mixture of cement and sand has to be poured in the container, 
Hence total weight on container including cement mixture $=2 \mathrm{~kg}$ of mortar $+1.5 \mathrm{~kg}$ (approx. weight of the container considering thin sheet material) $=3.15 \mathrm{~kg}$.

ii. Rope Design:

Maximum force acting on rope (Chain) which is used to lift the container upwards,

$$
\begin{aligned}
\mathrm{F}=\mathrm{W} * \mathrm{~g} & \\
& =3.5 * 9.81 \\
& =34.33 \mathrm{~N} .
\end{aligned}
$$

Total Length of the rope $($ Chain $)=$ $160 \mathrm{~cm}$.

iii. Motor Design:

- Here we are using two dc motors of $60 \mathrm{rpm}$ with power supply 12 volt, 5 amperes.

Weight $=13.4 \mathrm{Gms}$

Stall Torque $=1.8 \mathrm{~kg} / \mathrm{cm}$

Dead band $=1$ micro sec .

Max torque $=2.2 \mathrm{~kg} / \mathrm{cm}$

DC motor with gear box.

$$
\begin{aligned}
& \text { Motor weight }=145 \mathrm{Gms} \\
& \text { Torque }=3.5 \mathrm{~kg} / \mathrm{cm} \text { at } 12 \mathrm{v}, 60 \mathrm{rpm} \\
& \text { Load current }=350 \mathrm{Ma}
\end{aligned}
$$

\section{WORKING OF THE MACHINE}

Working of the machine starts as soon as the position of the machine is set. It should be brought close to the wall that is to be plastered, and it should stay fixed using the stoppers. After that, the plaster mixture i.e. mixture of cement and sand roughly in the portion of $4: 1$ is poured in the container i.e. the hopper. After that, with the help of rope coupled with the motor, this container i.e. hopper tray is pulled up or lifted up. The mixture of cement and send flows front and downwards on the wall due to gravitational force. The plate weld in the front side, which is used to push the mixture towards wall, applies pressure so that the cement sticks to the wall and it is properly addressed to the wall.

The particular thickness of the plaster i.e. to be achieved can be varied by varying clearance i.e. the distance between the machine and the wall. When the hopper tray is lifted up the plastering is done on the particular column of the wall, and when it comes down, the finishing and precision of the plastering is achieved. Once the plastering to the particular part of the wall is done, the machine can be moved horizontally, i.e. it slides to the left or right to plaster next respective column of the wall.

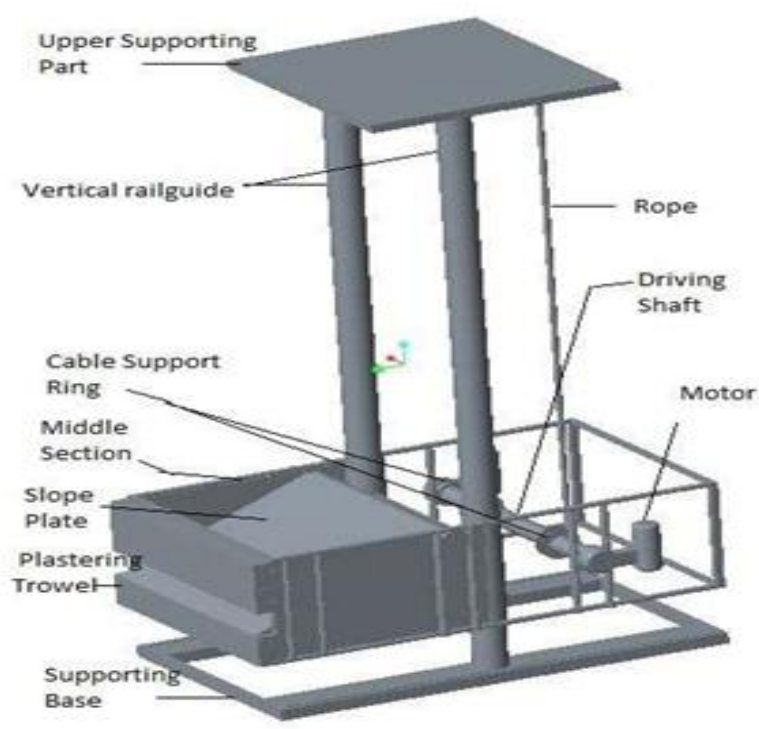

\section{Fig. Overall Structure of The Machine}

\section{ADAVANTAGES}

1. The manual plastering would vary the thickness at different wall but plastering machine can achieve any thickness constantly and uniformly.

2. The automatic plastering machines needs less time to complete plastering.

3. Machines is easy to operate and maintain as it can be controlled with remote.

4. Evolving the towards automation which increases the efficiency.

5. Wastages of the mixture in automatic plaster machine is about $0 \%$.

6. Manpower required is less.

7. Accuracy and precision is obtained which strengthens the infrastructure of the building and avoids hazards and risks to the human lives.

8. Quality of the work is obtained.

\section{DISADVANTAGES}

1. The machine has brought the automation in the process so there is less demand of labors which affects their job security.

2. The working of the machines stops in the absence of electricity.

3. The machine cannot be used where there is no electric supply continuity. 
4. Periodic maintenance of the machine has to be done to ensure proper working of the machine.

\section{CONCLUSION}

Automatic plastering machine has been developed successfully and is ideally suitable for the construction industry. Automatic plastering machine can improve the quality of the work with less wastage of material and with help of less no. of workers which can solve the problem of shortage of skilled labors.

Automatic plastering machine is fast and the quality of the work is superior as compared to the manual labor work.

Hence this machine can save time, money and gives us the change from the traditional manual technique to automated new technology which increases the efficiency and leads to growth of the nation.

\section{REFERENCES}

[1] Design and Fabrication of Wall Plastering Machine, Journal of Mechanical Engineering and Automation 2017, 7(5): 159-163.

[2] Design and Fabrication of Automatic Wall Plastering Machine, IJARIIE-ISSN, 02-2-17.

[3] Review Paper on Design of Automatic Wall Plastering Machine, International Journal for Scientific Research \& Development, 12-2018.

[4] Automatic Wall Plastering Machine, International Journal of engineering and Technical Research (IJETR), 1 January 2016.

[5] Automatic Plastering Machine, International Journal of Advance Research in Electronics, Communication \& Instrumentation Engineering and Development, $28^{\text {th }}$ July 2014. 